\title{
The repair of canalicular lacerations with an annular silicone tube and round-tipped pigtail probe
}

\author{
Fatih Mehmet Adibelli' ${ }^{1}$, Sevim Söker Çakmak ${ }^{1,2}$ \\ 'Department of Ophthalmology, School of Medicine, Harran University, \\ Sanliurfa, Turkey; ${ }^{2}$ Department of Ophthalmology, Medical Park Hospital, \\ Bahçelievler, Istanbul, Turkey
}

\begin{abstract}
Purpose: To analyze the outcomes of surgical repair of canalicular lacerations with a round-tipped pigtail probe and silicone tube implantation.

Methods: A retrospective review was conducted of the case records of 64 patients who presented to the Ophthalmology Department of Harran University between 2010 and 2015 and underwent surgical repair of canalicular lacerations. Each patient's age, gender, nationality, mechanism of injury, injured canaliculi, and follow-up time were evaluated. In addition to the anatomical and functional results, complications were also analyzed.

Results: A total of 64 patients, 51 (79.7\%) males and 13 (20.3\%) females, with a mean age at presentation of 14.6 years (range: 1-69 years) were enrolled. Forty-six patients were aged $<15$ years (71.9\%). Forty-two patients (65.6\%) had lower canalicular lacerations, and 19 patients had isolated upper canalicular lacerations (29.7\%). At the final follow-up (mean: 33.7 months), anatomical success was observed in all patients.

Conclusion: Silicone tube implantation using a round-tipped pigtail probe is an effective method that facilitates anatomical and functional success in cases of canalicular laceration.
\end{abstract}

Keywords: canalicular laceration, lacrimal canalicular surgery, ocular trauma, round-tipped pigtail probe

\section{Introduction}

Canalicular laceration is the most commonly observed form of injury in the lacrimal system and is seen in $36 \%$ of eyelid injuries. ${ }^{1}$ Although the eye trauma resulting from not repairing the obstruction and the associated epiphora can be seen at any age, it has been reported more often in the inferior canaliculus among those patients in the pediatric age group., ${ }^{2,3}$ The basic surgical principle of canalicular lacerations is based on providing the opportunity for the mucosa to recover by drawing the torn eyelid tissues together. ${ }^{4}$ Various methods have been

Correspondence: Fatih Mehmet Adibelli, Department of Ophthalmology, Harran University School of Medicine, Osmanbey Yerleskesi 63290, Sanliurfa, Turkey.

E-mail: fadibelli@gmail.com 
described for the repair of canalicular lacerations, which can be implemented with the assistance of the Quickert-Dryden probe, the Crawford stent, the Monoka stent, and a pigtail probe. ${ }^{5-7}$ The pigtail probe, which was first introduced by Worst, was later modified. ${ }^{8}$ Some authors suggest that the pigtail probe should not be used for repair because of the high risk of damage to the undamaged portion of the canalicular system. ${ }^{9,10}$ Complications may be seen in all the techniques used to repair canalicular laceration. ${ }^{11}$ Jordan et al. reported that to use a roundtipped pigtail probe is safe for canalicular laceration repair. ${ }^{12}$ Due to its practical efficiency, it is currently used as a preferred surgical method for repairing canalicular lacerations..$^{12-14}$

The aim of this study was to present the epidemiology of canalicular lacerations and the results of surgical repair with a round-tipped pigtail probe in cases that presented to the Ophthalmology Department of Harran University Hospital in the south eastern region of Turkey.

\section{Material and methods}

A retrospective evaluation was conducted on the records of 64 patients with canalicular lacerations following trauma between 2010 and 2015. Approval for the study was granted by the Clinical Research Ethics Committee of Harran University. The study included 64 eyes of 64 patients, where canalicular repair was done with the assistance of a round-end pigtail probe. A record was made of each patient's age, gender, the agent causing the injury, the affected eye, the affected canaliculus, the time to surgery, and other findings accompanying the canalicular injury. Patients with common canalicular injuries and those needing external dacryocystorhinostomy were excluded from the study.

In all patients, annular intubation was done with a silicone tube ( $\mathrm{FCl}$ Ophthalmics, Marshfield Hills, MA, USA) using a round-end pigtail probe under general anesthesia (Fig. 1). For 15 days postoperatively, tobramycin $0.3 \%$ eye drops were applied four times per day. Postoperative follow-up examinations were performed with fluorescein tests on patients aged $<10$ years and with lacrimal lavage in those aged $>10$ years. Follow-up examinations were made at one week and then at one, three, six, and 12 months postoperatively. The silicone tube was left in place for 12 months. Anatomic success was confirmed in cases where the canaliculus was open in tear duct irrigation, and anatomic and functional success consisted of no pooling in the fluorescein disappearing test and no tearing the eye.

\section{Surgical method}

All the cases were carefully examined once again under general anesthesia. All surgeries were performed by the same surgeon (SC). After expansion of the punctum with a dilator, the damaged canaliculus was reached by passing the 


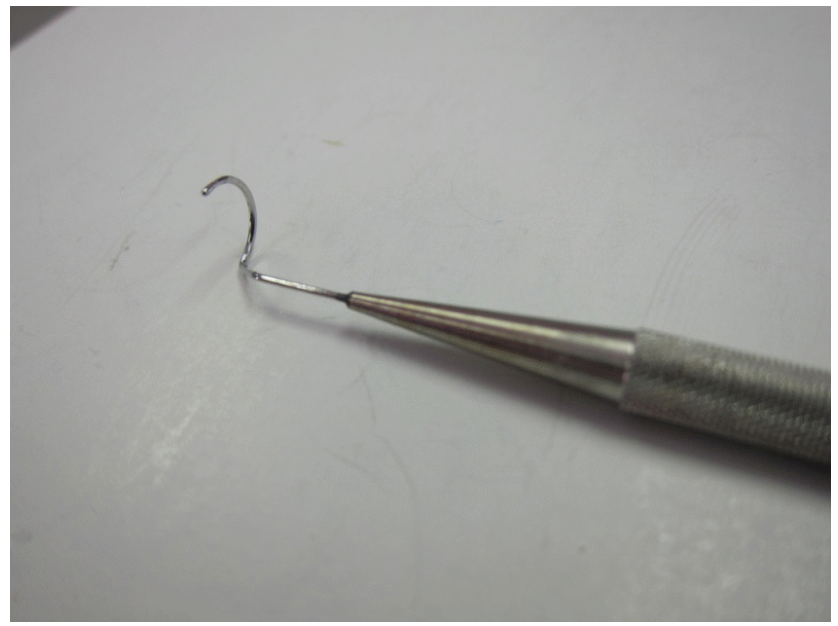

Fig. 1. A round-tipped pigtail probe.

round-tipped pigtail probe from the punctum of the healthy canaliculus (Fig. 2A). A $6 / 0$ prolene suture was passed from the hole at the end of the round-tipped pigtail probe into the spot where the silicone tube had been previously placed (Fig. 2B). When the round-tipped pigtail probe was drawn back inside the canaliculus, the silicone tube was also pulled together with the prolene suture (Fig. 2C). Then, the silicone tube was passed to the other end, assisted by the round-tipped pigtail probe from the punctum of the damaged canaliculus (Fig. 2D). Thus, the silicone tube passed both the upper and lower canaliculi. The $6 / 0$ prolene suture passing within the silicone was tightly bound end to end (Fig. 2E). The ends of the silicone remaining exposed were embedded within the canaliculus. The posterior and anterior sections of the lacerated canalicular wall were sutured with $8 / 0$ Vicryl and the skin laceration with $6 / 0$ prolene, and fixation was performed by drawing the wound lips together. The ends of the silicone tube were left at some length to prevent them from reaching the cornea and causing irritation (Fig. 2F). The average length of the tubing used in all patients was approximately $20 \mathrm{~mm}$, which was close to the mean value previously mentioned in the literature. ${ }^{14}$ The silicone tube was left in place for at least one year.

\section{Results}

The study included 64 patients, comprised 51 (79.7\%) males and 13 (20.3\%) females, with a mean age of $14.66 \pm 16.83$ years (range: $1-69$ years). Of the total number of patients, 46 (71.9\%) were aged $<15$ years. The mean follow-up period was $33.7 \pm 17.41$ months (range: $2-58$ months). The cause of the canalicular 


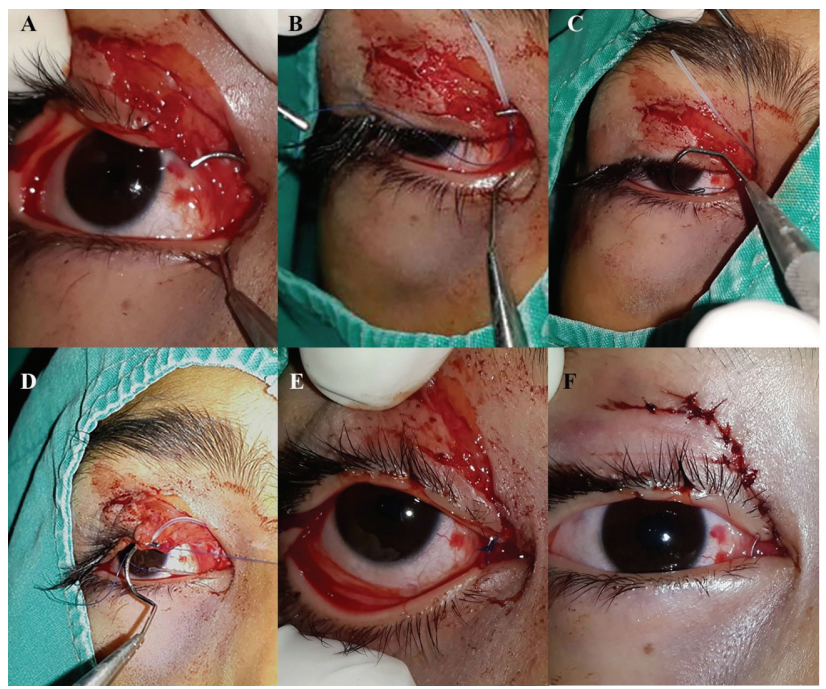

Fig. 2. Right upper lacrimal canalicular injury repairing with annular silicone tube and round-tipped pigtail probe.

laceration was associated with penetrating trauma in $36(56.3 \%)$ cases and with blunt trauma in 28 (43.8\%) cases. The laceration was in the lower canaliculus in 42 (65.6\%) cases, in the upper canaliculus in 19 (29.7\%) cases, and in both canaliculi in three $(4.7 \%)$ cases. In addition to canalicular laceration, eyelid laceration was confirmed in 15 (23.4\%) cases, conjunctival injury in seven (10.9\%), corneal injury in two (3.1\%), cornea-scleral laceration in one (1.6\%), extraocular muscle laceration in one (1.6\%), and frontal sinus fracture in one (1.6\%). At the final follow-up examination, traumatic ectropion was observed and associated with epiphora in one patient, and surgery was reperformed. In the follow-up of this patient, the epiphora appeared to be resolved. In one patient where a round-tipped pigtail probe had been applied for canalicular laceration at an external centre, the tube had not passed to the canaliculus; the tube was long, and as the suture had not been folded, it was then in contact with the cornea, thus causing irritation. The tube was reapplied with a round-tipped pigtail probe to pass from the canaliculus, and the length was shortened. In the follow-up period, no epiphora was observed. At the end of the one-year follow-up after removal of the silicone tube, no cases of anatomical or functional failure were observed.

\section{Discussion}

Canalicular injuries have been reported as constituting $15.5 \%$ of all eyelid injuries. ${ }^{15}$ Lacrimal canalicular laceration is the most frequently seen injury of the lacrimal 
system. In a study of 25 cases, Wulc et al. reported that as the canalicular region includes less connective tissue compared to the tarsal region, injuries associated with trauma occur more easily, and the most common cause of canalicular laceration, at a rate of $84 \%$, was blunt trauma. ${ }^{16}$ In contrast, Jordan et al. reported that canalicular tears developed as a result of penetrating trauma in $55.2 \%$ of 236 cases. ${ }^{17}$ In this study, the injuries were found to be associated with penetrating trauma in 36 (56.3\%) cases and with blunt trauma in 28 (43.8\%) cases, which are rates closer to those of the second above-mentioned study.

It is possible to prevent epiphora following trauma with correct diagnosis and an appropriate surgical approach. Some authors have stated that the lower canaliculus is important and therefore prefer not to use a probe in the repair of the upper canaliculus. Other authors have reported that tear drainage has a significant role in the function of both canaliculi. ${ }^{4,18-20}$ In previous studies, there have been more reports of canalicular lacerations in the lower canaliculus.,12 In this study, lacerations of the lower canaliculus were seen twice as much as that of the upper canaliculus. Furthermore, the laceration was in the lower canaliculus in $42(65.6 \%)$ patients and in the upper canaliculus in 19 (29.7\%) patients.

In a study of 13 patients, Smit and Mourits repaired mono-canalicular lacerations with cutaneous and subcutaneous sutures only, without the application of silicone tube. ${ }^{21}$ This study concluded that despite the observation of epiphora, this method had not caused great discomfort, and it was also stated that some cases were of "familial" causes. In response to criticisms of this application, it was stated that because of the length of ophthalmology operating lists and the risks of treatment, this particular approach could be considered a viable surgical option. ${ }^{21}$ In contrast, in a study by Jordan, it was reported that although same-day canalicular repair is not mandatory, better results are obtained in cases treated within seven to 10 days. ${ }^{22}$ In one of the cases in this study, canalicular laceration repair had been performed at an external center one week previously, but the patient had complaints of stinging and epiphora. As the knots of the suture joining the silicone tube had not been turned inside the canaliculus, this was causing irritation, and the silicone tube itself was not within the canaliculus. After the intervention in our clinic, anatomic and functional success was observed in the follow-up. This case can be considered as good evidence confirming the claim that rather than doing nothing, and even if there is a delay of a few days, the patient should still be referred to a center where canalicular repair can be effectively performed.

Ultimately, there are three basic principles for successful canalicular repair: (i) end-to-end proximity of the lacerated parts, (ii) endo-canalicular support with the silicone tube, and (iii) an atraumatic approach to the non-injured side of the lacrimal system. ${ }^{12}$ With functional and anatomic success obtained for all of the present study's patients, the use of the round-end pigtail probe and silicone tube 
can be considered to have met these three principles. Epiphora was only observed in one $(1.8 \%)$ of the patients. The reason for epiphora in this case was associated not with the canaliculus, but with traumatic ectropion, which was corrected with surgery; at the end of the one-year follow-up, there was no further complaint of epiphora. To corroborate the results presented here, one of the largest case series in the literature using a round-tipped pigtail probe in canalicular laceration repair was by Jordan et al., where the success rate was reported as $97.4 \%$ with the application of this method. ${ }^{14}$

The limitation of this method have been reported as involving the risk of damage to the healthy canaliculus or to the common canaliculus, the risk of opening the wrong passage, and that the method cannot be used in individuals with no common canaliculus. ${ }^{14,20-23}$ The pigtail probe cannot be used in patients without common canaliculus because there is no anatomic patency to allow the probe to pass. In our practice, we have used a round-end pigtail probe in all cases of isolated canalicular laceration without encountering any of these disadvantages, but we still prefer not to use the method in patients with laceration of the common canaliculus. In a study of 18 cases of canalicular laceration repaired with the assistance of a round-tipped pigtail probe, success was reported for $100 \%$ of the patients, and in another study of 22 cases, the success rate was $94 \% .^{12,24}$ In this study of 64 cases, a success rate of $100 \%$ was achieved both anatomically and functionally.

Some authors have claimed that as there is a traumatic effect on the healthy canalicular system, the results of the pigtail probe may not be satisfactory, and the method should be abandoned. ${ }^{9,20}$ These comments are most likely formed in reference to the single round-tipped pigtail probe and, more specifically, directed at the "hook-end" pigtail probe introduced by Worst. ${ }^{8}$ With the use of a round-tipped pigtail probe, may be, the anatomical and functional success rates are still extremely high. ${ }^{8,13,22}$ Reasons for unsuccessful surgeries may include the severity of the trauma and the use of other material in place of the silicone stent. That the silicone stent within the lumen does not create any narrowing of the canalicular wall is extremely important in terms of facilitating the healing process. In an animal experimental study by Snead et al., it was shown that the silicone tube within the canaliculus was maintained in a stable position with the blink reflex without any effect on epithelialization..$^{25}$ Therefore, in this study, the silicone tube was left in place within the canaliculus for one year, and this can be considered to have had as much of an effect on the functional success as the surgical approach itself.

Although the duration of the silicone tube is generally recommended as six months, in some series, cases with recurrent tearing after removal of the silicone tube even after 10 months have been mentioned. ${ }^{14}$ The reason why we prefer the duration of the silicone tube as 12 months is to avoid recurrent punctal closure, 
re-stenosed, canalicular narrowing, and intermittent tearing. We think that the biggest reason for our success in our cases is due to the duration of this silicon tube.

In conclusion, in cases of traumatic canalicular laceration, annular silicone placement with a round-tipped pigtail probe is a surgical method which can be quickly learned and easily applied, with low costs and high success rates. Thus, its current use remains justified. It should be noted that the learning curve is not long since the residents have very short time to learn this surgical method.

\section{References}

1. Naik MN, Kelapure A, Rath S, Honavar SG. Management of canalicular lacerations: epidemiological aspects and experience with Mini-Monoka monocanalicular stent. Am J Ophthalmol. 2008;145(2):375-380.

2. Reifler DM. Management of canalicular laceration. Surv Ophthalmol. 1991;36(2):113-132.

3. Kennedy RH, May J, Dailey J, Flanagan JC. Canalicular laceration. An 11-year epidemiologic and clinical study. Ophthal Plast Reconstr Surg. 1990;6(1):46-53.

4. Jones LT, Marquis MM, Vincent NJ. Lacrimal function. Am J Ophthalmol. 1972;73(5):658-659.

5. Quickert MH, Dryden RM. Probes for intubation in lacrimal drainage. Trans Am Acad Ophthalmol Otolaryngol. 1970;74(2):431-433.

6. Crawford JS. Intubation of obstructions in the lacrimal system. Can J Ophthalmol. 1977;12(4):289-292.

7. Fayet B, Bernard JA, Pouliquen Y. Repair of recent canalicular wounds using a monocanalicular stent. Bull Soc Ophtalmol Fr. 1989;89(6-7):819-825.

8. Worst JG. Method for reconstructing torn lacrimal canaliculus. Am J Ophthalmol. 1962;53:520-522.

9. Saunders DH, Shannon GM, Flanagan JC. The effectiveness of the pigtail probe method of repairing canalicular lacerations. Ophthalmic Surg. 1978;9(3):33-40.

10. Welham R. The immediate management of injuries to the lacrimal drainage apparatus. Trans Ophthalmol Soc UK. 1982;102:216.

11. Anderson RL, Edwards JJ. Indications, complications and results with silicone stents. Ophthalmology. 1979;86(8):1474-1487.

12. Jordan DR, Nerad JA, Tse DT. The pigtail probe, revisited. Ophthalmology. 1990;97(4):512-519.

13. Beyer CK. A modified lacrimal probe. Arch Ophthalmol. 1974;92(2):157.

14. Jordan DR, Gilberg S, Mawn LA. The round-tipped, eyed pigtail probe for canalicular intubation: a review of 228 patients. Ophthal Plast Reconstr Surg. 2008;24(3):176-1780.

15. Herzum H, Holle P, Hintschich C. Eyelid injuries: epidemiological aspects. Ophthalmologe. 2001;98(11):1079-1082.

16. Wulc $A E$, Arterberry JF. The pathogenesis of canalicular laceration. Ophthalmology. 1991;98(8):1243-1249.

17. Jordan DR, Ziai S, Gilberg SM, Mawn LA. Pathogenesis of canalicular lacerations. Ophthal Plast Reconstr Surg. 2008;24(5):394-398.

18. Ho T, Lee V. National survey on the management of lacrimal canalicular injury in the United Kingdom. Clin Exp Ophthalmol. 2006;34(1):39-43.

19. Linberg JV, Moore CA. Symptoms of canalicular obstruction. Ophthalmology. 1988;95(8):1077-10789.

20. Canavan YM, Archer DB. Long-term review of injuries to the lacrimal drainage apparatus. Trans Ophthalmol Soc UK. 1979;99(1):201-204. 
21. Smit TJ, Mourits MP. Monocanalicular lesions: to reconstruct or not. Ophthalmology. 1999;106(7):1310-1312.

22. Jordan DR. To reconstruct or not. Ophthalmology. 2000;107(6):1022-1023.

23. Hing SJ. A retrospective study of lacrimal canaliculus injuries in Auckland. Trans Ophthalmol Soc N Z. 1984;36:72-73.

24. Walter WL. The use of the pigtail probe for silicone intubation of the injured canaliculus. Ophthalmic Surg. 1982;13(6):488-492.

25. Snead JW, Rathbun JE, Crawford JB. Effects of the silicone tube on the canaliculus: an animal experiment. Ophthalmology. 1980;87(10):1031-1036. 